\title{
Emerging approaches toward the treatment of neurofibromatoses
}

Frank Liebermann, $M D^{1}$, and Bruce R. Korf, $M D, P h D^{2}$

As the molecular advances of the last decade are applied to the treatment of neoplasms associated with neurofibromatosis, patients and the physicians who treat them are anticipating the arrival of safe and effective agents specifically targeted to the defects in control of cell growth and differentiation. For the first time, drug design can be based on an understanding of the molecular defects involved in the pathogenesis of the neoplasms. More powerful and selective modulators of the host immune response to tumor cells may allow selective immunotherapy. Gene transfer technology may be used to express regulatory proteins that inhibit tumor cell proliferation, induce apoptosis, or make the tumor cells more selectively immunogenic to the host. There is indeed much cause for optimism and intellectual excitement.

However, lessons learned from the initial attempts to apply these treatment strategies to other types of cancer argue that we must anticipate that the translation of molecular approaches to the clinical treatment of NF related neoplasms will be difficult. ${ }^{1}$ Advances will be incremental and the complexity of the disease and the mechanisms used to treat it will make careful study of the reasons for failure as important as the successes. As we begin to prioritize candidate strategies for clinical trials, the biologic constraints of the disease and the treatment strategies should be carefully considered.

\section{MEDICAL BURDEN OF NF1 AND NF2}

NF1 is a multisystem disorder that affects the central and peripheral nervous systems, skin, bone, and the eye. ${ }^{2}$ The hallmark is the occurrence of peripheral nerve sheath tumors called neurofibromas. These may arise along nerves anywhere in the body. Most are asymptomatic, but clinical problems may include cosmetic and severe disfigurement, functional impairment of a limb, airway or gastrointestinal obstruction, paralysis, and pain. Symptoms can be particularly troublesome for plexiform neurofibromas. These tumors involve multiple fascicles of a nerve and may extend along a length of a nerve and involve multiple branches. Some can grow to massive size and cause hypertrophy of part of the body. Other complications of NF1 include skeletal dysplasia, ${ }^{3}$ learning disabilities, ${ }^{4,5}$ and malignant gliomas and peripheral nerve sheath tumors. ${ }^{6}$ The disorder tends to be progressive, although there is a wide range of variability of expression. ${ }^{7}$ Major features of morbidity and mortality caused by NF1 are listed in Table 1.

'Department of Neurology, Mt. Sinai School of Medicine, New' York, NY, and 'Division of Genetics, Children's Hospital and Harvard Medical School, Boston, Massachusetts

Dr. Bruce R. Korf. Children's Hospital, 300 Longwood Avenue, Boston, MA 02115-5737. Subinitted for consideration April 7, 1999; accepted for publication April 12, 1999.
NF2, in contrast, is almost entirely a disorder of tumor formation. ${ }^{8}$ The only common nontumor manifestation is cataract. ${ }^{9}$ Tumors include schwannomas of cranial and peripheral nerves, meningiomas, ependymomas, and gliomas. Bilateral deafness is common, and facial paralysis is also a frequent complication. This, too, is a progressive disorder and is commonly associated with significant neurological disability. Major morbidity associated with NF2 is listed in Table 2.

\section{PATHOGENESIS OF NF1 AND NF2}

Virtually all of the knowledge about the pathogenesis of NF1 and NF2 is derived from studies performed since the genes were cloned. The NF1 gene is located on chromosome 17 and encodes a 2818 amino acid protein called "neurofibromin." ${ }^{10-12}$ The NF2 gene is located on chromosome 22 and encodes a protein referred to as "merlin" or "schwannomin." 13,14 The fundamental pathogenetic mechanism underlying tumors in both disorders is believed to be via a tumor suppressor mechanism (figure 1). This

Table 1

Major complications associated with neurofibromatosis type 1

\begin{tabular}{ll}
\hline System & Complication \\
\hline Central nervous system & $\begin{array}{l}\text { Optic glioma; astrocytoma; learning } \\
\text { disability; cord compression }\end{array}$ \\
Peripheral nervous system & $\begin{array}{l}\text { Nerve compression } \\
\text { Cutaneous }\end{array}$ \\
$\begin{array}{l}\text { Cosmetic impairment due to } \\
\text { neurofibromas; pruritis }\end{array}$ \\
Orthopedic & $\begin{array}{l}\text { Limb overgrowth; scoliosis; long bone } \\
\text { dysplasia }\end{array}$ \\
Vascular & $\begin{array}{l}\text { Stroke; hypertension; aneurysm } \\
\text { Endocrine }\end{array}$ \\
Gastrointestinal & Precocious puberty \\
Ophthalmologic & Constipation; obstruction \\
\hline
\end{tabular}

Table 2

Major sources of morbidity associated with neurofibromatosis type 2

\begin{tabular}{ll}
\hline System & Complication \\
\hline Central nervous system & $\begin{array}{l}\text { Vestibular schwannoma; other } \\
\text { schwannomas; glioma; ependymoma; } \\
\text { meningioma }\end{array}$ \\
Peripheral nervous system & Schwannoma \\
Cutaneous & Cutaneous schwannoma \\
Ophthalmologic & Cataract \\
\hline
\end{tabular}




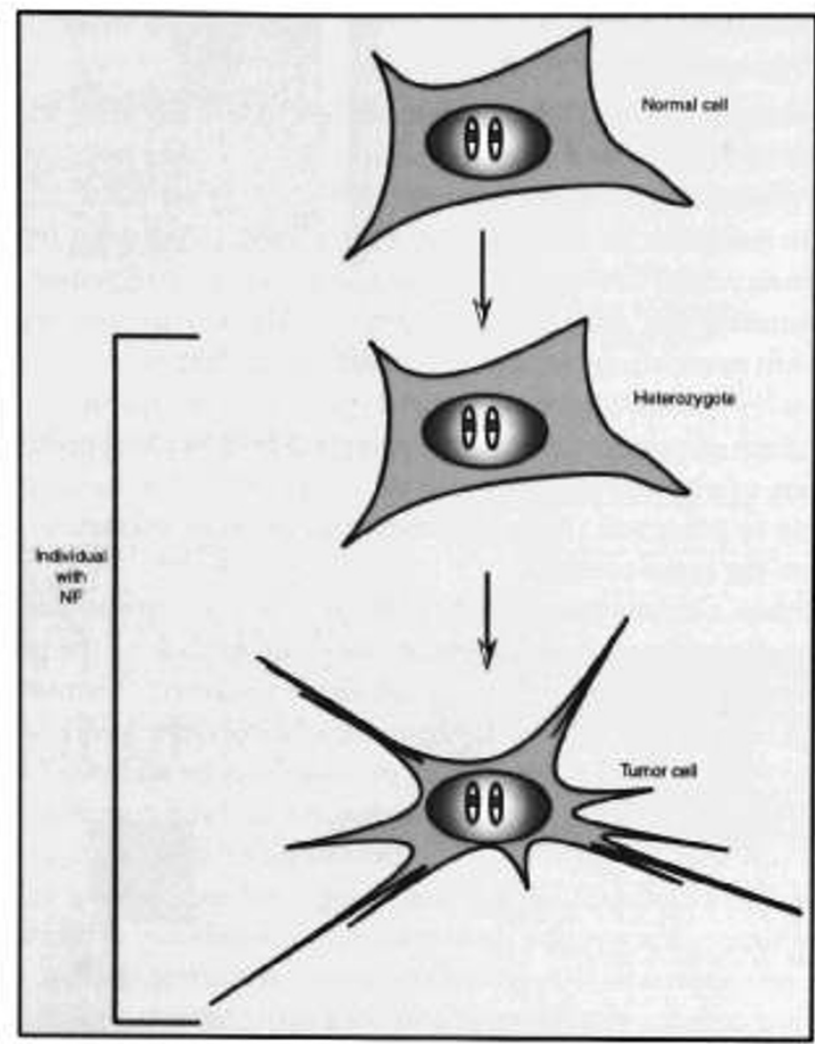

Fig. 1 Tumor suppressor hypothesis as applied to NFl and NF2. Tumors associated with neurofibromatosis are presumed to have inactivating mutations in both NF alleles (indicated by red). Individuals with neurofibromatosis have one germline mutation, leading to an increased frequency of tumors caused by loss of the remaining functional copy of the NF1 or NF2 gene. Persons who do not have NF must first acquire one mutation and subsequently another in the same cell lineage to develop a neurofibroma or schwannoma. Such tumors are therefore rare in the general population.

is very well supported for NF2, where tumors in patients tend to show loss of heterozygosity ( $\mathrm{LOH}$ ) for markers on chromosome $22 .^{15,16}$ For NF1, LOH involving the NF1 region of chromosome 17 has been seen in malignant tumors and some benign neurofibromas. ${ }^{17-19}$ Neurofibromas contain multiple cell types, so cellular heterogeneity may account for some of the difficulty in detecting LOH. It remains possible that heterozygous NF1 mutation itself accounts for some phenotypic effects. Most NF1 germline mutations lead to premature termination of translation, ${ }^{20}$ so haploinsufficiency rather than dominant negative effects would be the postulated mechanism. This may be a particularly attractive hypothesis for the nontumor manifestations, such as learning disability.

The NF1 gene includes a domain with GTPase activating protein (GAP) function. ${ }^{21-23}$ This GAP domain is functional and regulates GTPase activity for p21RAS. The NF1 protein binds tubulin, ${ }^{24}$ but the function of areas of the protein outside the GAP domain is unknown. Current pathogenetic hypotheses therefore focus on the regulation of RAS (Figure 2). GAP proteins regulate RAS by stimulating the intrinsic GTPase in RAS to convert the active RAS-GTP form to the inactive RAS-GDP form. It is hypothesized that loss of neurofibromin leads to inability to inactivate RAS-GTP, leading to high levels of expression and consequent tumor formation. High levels of RAS-GTP indeed

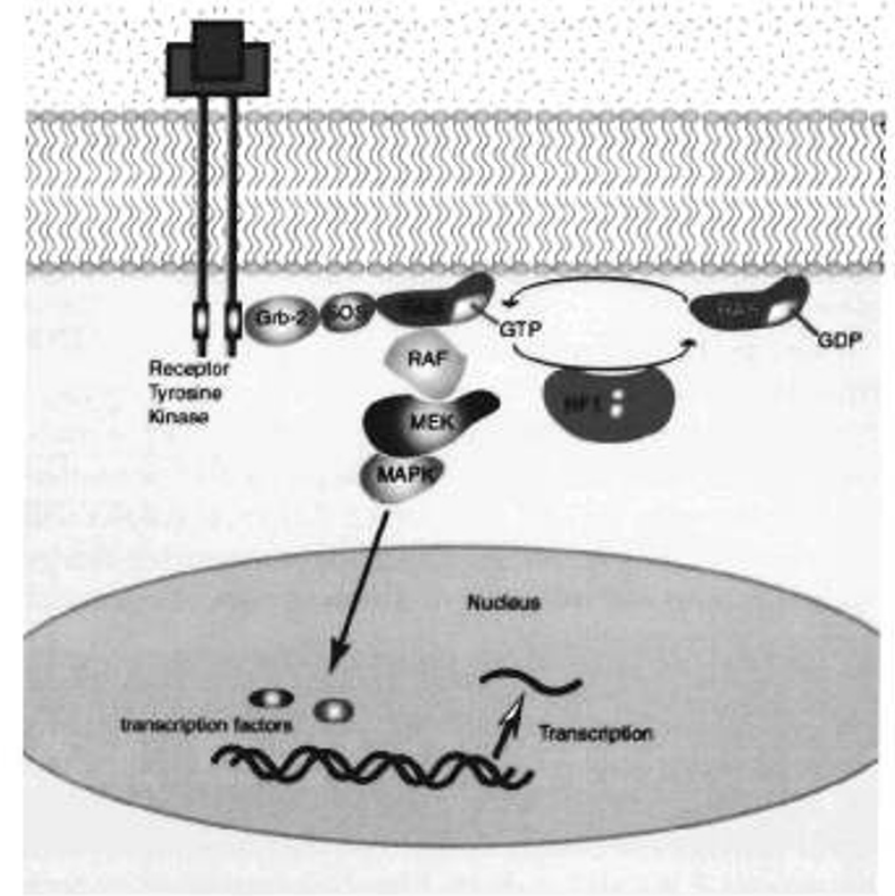

Fig. 2 Function of NF1 gene product in regulation of RAS. A ligand binds a receptor on the cell surface, which leads to activation of tyrosine kinase. Grb-2 binds with phosphorylated proteins and activates SOS (son of sevenless), which leads to activation of RAS through binding to GTP. Activated RAS binds to RAF-1, which activates MEK, leading to activation of MAP kinase (MAPK). MAPK then transduces a signal to the nucleus, leading to transcription of specific proteins. The NF1 gene product is a GTPase activating protein, which stimulates intrinsic RAS GTPase, leading to inactivation of RAS by conversion of GTP to GDP.

have been found both in malignant and non-malignant NF1 tumors. ${ }^{25}$ The exact mechanism whereby failure to inactivate RAS leads to abnormal behavior of nerve sheath cells is unknown.

The NF2 gene product is a cytoskeletal protein, homologous to members of the protein 4.1 family, including ezrin, radixin, and moeisin (figure 3). ${ }^{13}$ It co-localizes in the cell with actin ${ }^{26}$ and may be involved in the membrane changes that occur with cellular responses to extrinsic signals. The mechanism whereby loss of function of the NF2 product leads to tumor formation is unknown, however.

\section{OUTCOMES MEASUREMENT IN CLINICAL TRIALS}

Both NF1 and NF2 pose special challenges in definition and measurement of outcomes that will need to be faced before clinical trials can be undertaken. Growth of tumors can be very slow

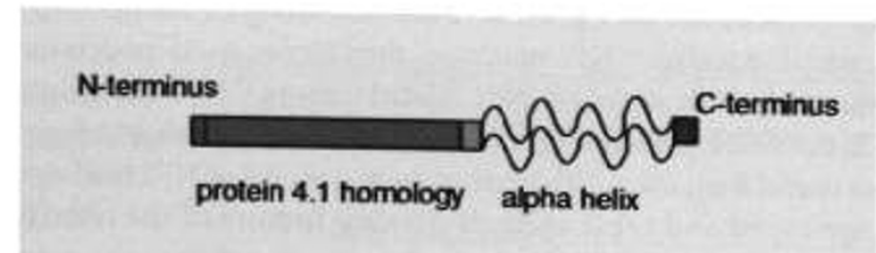

Fig. 3 The NF2 protein includes a region of homology with proteins of the protein 4.1 family an alpha helical domain and a C-terminal domain. There are also binding sites both for actin and tubulin. (Adapted from M. MacCollin, "Report of House Ear Institute/National Neurofibromatosis Foundation meeting on NF2" and I.-M. Xu, and D. H Gutmann, "Merlin differentially associates with the microtubule and actin cytoskeleton." J Neurosci Res 1998;51:403-415.) 
and unpredictable, and in some instances can remit spontaneously. This will make it important to have data on natural history, lest spontaneous cessation of tumor growth be mistakenly attributed to the effects of a drug being tested. The tumors may be large and irregularly shaped, especially for plexiform neurofibromas in NF1. This makes it difficult to accurately measure tumor size, which will be necessary in documenting the efficacy of treatment.

These problems are currently being addressed in a pair of natural history studies funded by the U.S. Army Medical Research Command. Both are using volumetric MRI to study the growth of either plexiform neurofibromas in NF1 or vestibular schwannomas in NF2. It is hoped that these studies will establish the utility of this imaging mode in measuring change in these tumors and will generate a body of normative data on patterns of tumor growth.

Another challenge is the fact that both disorders tend to be lifelong and progressive. Any therapy that does not permanently ablate all tumors and potential tumors will need to be continued over a long period of time, perhaps a lifetime. This severely limits the degree of acceptable toxicity for potential drugs used for treatment. It is also unclear whether treatments will be cytostatic or cytotoxic. If the former is the case, it is likely that treatments will be more effective at preventing tumor growth than at reversing already established tumor bulk. This may require treatment of young children before onset of severe symptoms, which again requires a low level of toxicity and knowledge of the natural history to predict which patients will develop large or numerous tumors.

Because NF1 may become symptomatically progressive in pediatric patients and adults, phase 1 studies, which determine the pharmacodynamics and pharmacokinetics of candidate agents, must be performed in both adults and children. The FDA requires pediatric phase 1 testing for any agent that will be used in children. Formulation is important in pediatric trials. Treatments that require frequent intravenous dosing, continuous intravenous infusion, or even multiple daily oral dosing are cumbersome for adults and may be prohibitively cumbersome or disruptive for children. Of course a truly effective and safe agent would justify significant inconvenience, but in choosing candidate agents for therapeutic trials in children, the impact on quality of life must be an important consideration.

Rational drug development for the treatment of NF1 and NF2 is hampered by the lack of representative and easily manipulated animal models. Although knockout mice homozygous for deletion of the NF1 gene have allowed study of the developmental sequelae of NF1 mutation, they are not good models for the study of treatment of NF1 related tumors. ${ }^{27} \mathrm{NF} 1$ knockouts do not develop neurofibromas or astrocytomas with short latency or useful frequency. Although an animal model of NF2 has been developed and these animals develop tumors of the cranial nerves, which resemble human schwannomas, these tumors do not develop in a high percentage of animals. ${ }^{28}$ In addition, tumor latency is too long for drug testing. Unfortunately, the lack of an animal model makes it difficult to prioritize drugs for entry into clinical trial.

\section{Clinical Trials for NF1}

\section{Malignant Tumors}

Although a feared complication, malignancy is rare in patients with NF1. Acute myelogenous leukemia (AML) ${ }^{29}$ and malignant peripheral nerve sheath tumors (MPNST) are the most common malignancies. Patients with AML and NF1 frequently have chromosomal abnormalities associated with poor response to chemotherapy, such as monosomy $7 .^{30}$ MPNST usually arise within preexisting plexiform neurofibromas, but may arise de novo. ${ }^{31,32}$ MPNST arise as localized tumors, often causing exacerbation of pain, preexisting neurologic deficit, or rapid growth in size of a known plexiform neurofibroma. MPNST behave similarly to other soft tissue sarcomas, and systemic metastasis is often the cause of death.

When a locally resectable MPNST is removed, current adjuvant chemotherapeutic regimens have little impact on the risk of recurrence, similar to other soft tissue sarcomas. ${ }^{33}$ Somatic gene transfer strategies and immunomodulators may have a role in management of MPNST. This problem may be addressed by using a tumor vaccine strategy, analogous to those currently in clinical trial for patients with melanoma or colon cancer. ${ }^{34}$ Cytokine based cellular vaccines, using autologous tumor cells and vectors transferring various immunostimulatory cytokines are one approach; these protocols require culturing autologous tumor cells for gene transfer and then subcutaneous injection after irradiation of the tumor cells. Alternatively, killed tumor cell vaccines administered with adjuvant may be another approach. ${ }^{35}$ An adjuvant-killed tumor cell vaccine protocol for patients with locally resected soft tissue sarcomas is planned at the University of Pittsburgh, Pittsburgh Cancer Institute.

\section{Neurofibromas}

The role of NF1 in the regulation of RAS makes this pathway a prime target for therapeutic manipulation. For RAS mediated signal transduction to propagate, the activated RAS molecule and linking proteins must be translocated to the inner surface of the cytoplasmic membrane and fixed there by attachment of a long chain fatty acid, farnesyl (Figure 4), through the action of enzymes referred to as farnesyl protein transferases. ${ }^{36}$ Three pharmaceutical companies have farnesyl transferase inhibitors (FTI) in development as anti-cancer drugs. A phase 1 study of one FTI is currently underway in the Pediatric Branch of the National Cancer Institute for children with progressive PN. This drug is administered orally. The investigators anticipate that the maximum tolerated dose for the phase 2 trial of potential efficacy will be completed within the next 6 months. Although the enzymatic pathway for regenerating retinal photoreceptor pigment also involves a farnesylation step, no visual toxicity has been observed to date in the phase 1 trial. If successful, the FTI will represent one of the first applications of molecularly targeted therapy to the treatment of human neoplasms. Because recent observations implicate the RAS signaling pathway in both NF1 related and sporadic astrocytomas, FTI may have important applications beyond the treatment of PN. ${ }^{37}$

A number of agents that have been tested for other cancer treatment indications may be applied to the treatment of 


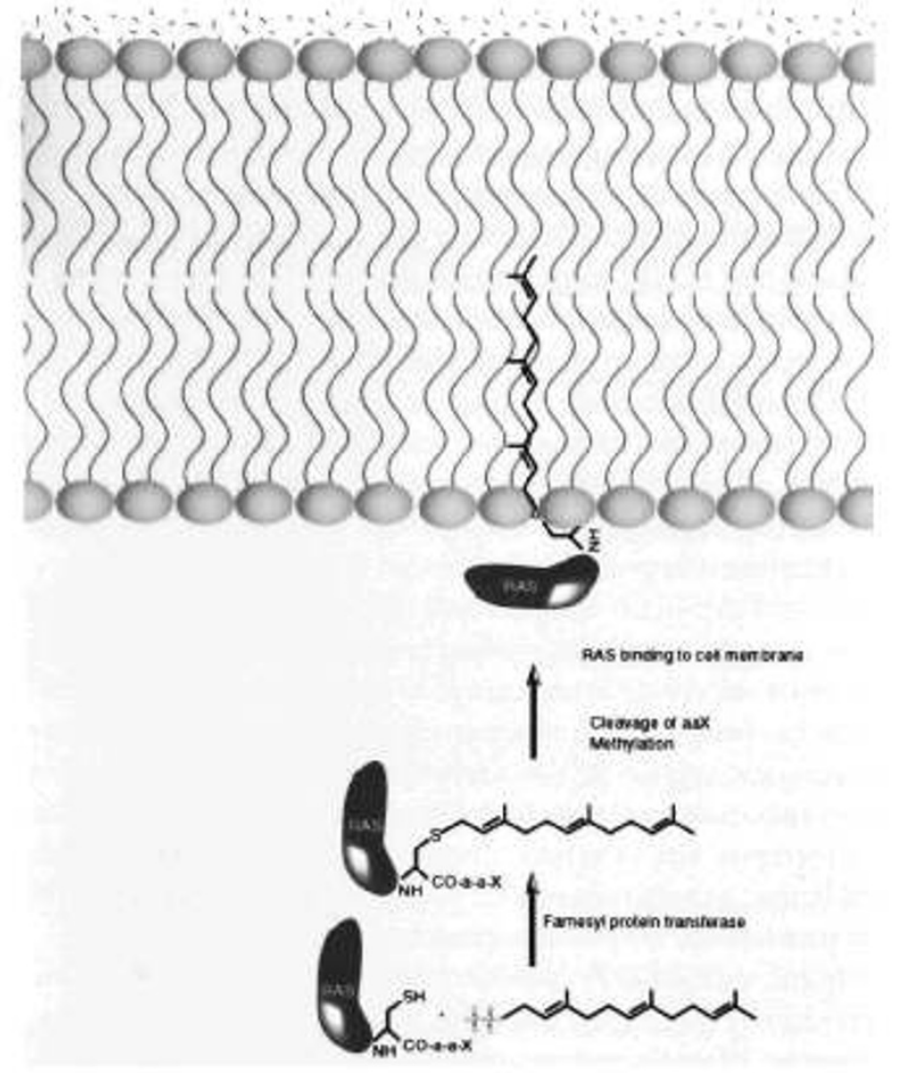

Fig. 4 Binding of RAS to inner cell membrane by farnesylation reaction. The enzyme farnesyl protein transferase recognizes proteins with a CaaX C-terminal sequence ( $C$, cys; a, aliphatic amino acid; $X$, another amino acid) and covalently attaches a 15 carbon isoprenyl group (farnesyl). The aaX group is then removed, and the protein is methylated. This complex is then bound to the inner cell membrane. Inhibitors of the farnesyl protein transferase enzyme result in inability of RAS to bind to the membrane.

plexiform neurofibromas. Because these agents already have phase 1 safety and dosing data available, efficacy studies are straightforward. In considering the prioritization of testing such agents, preclinical efficacy in animal or in vitro models, toxicity profile, and convenience of administration are all relevant concerns.

Differentiation inducers are drugs that inhibit tumor cell proliferation and induce phenotypic changes associated with a mature neuronal or glial cell. Clinically relevant differentiation inducers include the retinoids, polar-nonpolar compounds, and short chain aromatic fatty acids. The prototypic differentiation inducers are the retinoids, a family of molecules related to vitamin A, whose cellular expression is normally developmentally regulated.

All trans retinoic acid (ATRA) has become first line therapy for patients with acute promyelocytic leukemia (APL) and has also been tested in phase 2 studies in patients with recurrent malignant astrocytoma. ${ }^{38}$ Treatment with ATRA increases time to progression in patients with recurrent malignant astrocytoma. ${ }^{39}$ Retinoids act though interaction with a multimember family of receptors. ${ }^{40}$ Selectivity of response is determined in part by preferential affinity for different subclasses of receptors, which dimerize after ligand binding and translocate to the nucleus of the cell. Various heterodimer or homodimer complexes then react with varying affinity to different retinoic acid binding domains in nuclear DNA; the retinoic acid binding domains are transcriptional regulators for a variety of genes involved in regulation of cell proliferation or cellular phenotype. A related retinoid, 13-cis retinoic acid, has similar effects in patients with recurrent malignant astrocytomas ${ }^{41}$ and 9-cis retinoic acid has been tested in patients with lung cancer in phase 1 studies. ${ }^{42}$ Ideally, a differentiation inducer should produce terminal differentiation and loss of proliferative potential or induce apoptosis. When a differentiation inducer does neither, continued administration may be required to maintain the antiproliferative effect. In APL, treatment with ATRA does induce terminal differentiation, but in treatment of neuroectodermal tumors, treatment effect is transient. In vitro studies of astrocytoma and medulloblastoma derived cell lines demonstrated loss of antiproliferative effects after washout of ATRA. ${ }^{43}$ In treatment of PN, continued administration would probably be required. The regimen used in treatment of anaplastic astrocytoma is $50 \mathrm{mg} / \mathrm{m}^{2}$ bid for 21 days followed by a 7 -day rest to complete one cycle. There is minimal myelosuppression with retinoid treatment. The most common toxicity is cheilosis; headache is also frequent and may be mistaken for tumor related increased intracranial pressure. This syndrome is similar to the pseudotumor cerebri seen in patients taking supraphysiologic doses of vitamin A. All the retinoids are powerful teratogens. These drugs must be tested with extreme care in women of childbearing age. Females participating in such trials should have a pregnancy test documented before study entry and use effective contraception during treatment.

The short chain aromatic fatty acids phenylacetate (PA) and phenylbutyrate (PBA) induce differentiation and inhibit proliferation of a wide range of neoplastic cell lines in vitro, including astrocytoma, neuroblastoma, and medulloblastoma. ${ }^{44} \mathrm{PA}$ and PBA have been tested in phase 1 trials of malignant glioma, and PBA has a well-established safety record, being used to treat neonatal hyperammonemia associated with urea cycle abnormalities. PA must be given as a continuous intravenous infusion because of its short half-life in serum; PBA is available in both intravenous and oral formulations. In most in vitro systems, $\mathrm{PBA}$ is more potent on a molar basis than PA, but PBA is rapidly metabolized to PA in serum. Although the results of a phase 2 study of phenylacetate for patients with recurrent malignant astrocytoma are disappointing, a more intense dosing schedule is currently being evaluated. ${ }^{45}$ Phenylbutyrate, which is more potent in vitro on a molar basis than phenylacetate, ${ }^{44}$ warrants further evaluation in the treatment of malignant glioma. A phase 1 trial of PBA for patients with progressive plexiform neurofibroma has begun at the Pediatric Branch of the NCI.

In a number of in vitro systems, including human leukemia derived cell lines and colon cancer cell lines, sequential treatment with a cytotoxic chemotherapeutic drug and then a differentiation inducer increases the potency of the differentiation inducer. A phase 1 trial of 5-flurouracil (5-FU) followed by intravenous phenylbutyrate is underway at Mt. Sinai Medical Center, New York, NY for patients with metastatic colon cancer. Although cytoreductive drugs, especially alkylating agents, are contraindicated in patients with NF1, combination strategies might be considered for NF1 associated astrocytomas. Because carboplatin 
and vincristine or etoposide are commonly used for progressive pediatric low-grade astrocytomas, ${ }^{46}$ combination therapy with carboplatin followed by PBA may be a reasonable approach to test in phase 1 trials.

Antiangiogenesis agents are being tested in animal models of a variety of high grade neoplasms, including malignant gliomas. ${ }^{47}$ These drugs interfere with one or more of the signaling molecules, which induce new blood vessel formation in the vicinity of growing tumors. A number of agents are in preclinical development, including angiostatin and endostatin. Thalidomide acts as an antiangiogenesis agent in animal models of some tumor types, including malignant glioma, and a phase 1 trial of thalidomide for patients with progressive plexiform neurofibroma is accruing patients in a Childrens' Cancer Study Group trial. ${ }^{48}$ Thalidomide has recently become commercially available for a nononcologic indication; the usual dose limiting toxicity is sedation. Of course, the drug must be used with extreme caution in women of childbearing age. Antiangiogenesis agents cannot be evaluated in in vitro tumor cell models, since the phenomena of tumor induced angiogenesis can only be studied in animal models of growing solid tumors. The role of angiogenesis in progression $\mathrm{PN}$ is probably minimal, because these slow growing neoplasms do not demonstrate significant neovascularity. In patients with MPNST, antiangiogenesis agents are conceptually applicable. Since the statin drugs are difficult synthetic challenges, these drugs will be in short supply for clinical trials and will probably be tested in patients with more common refractory malignancies such as lung or breast cancer. Other agents are being developed that inhibit signal transduction through the vascular endothelial growth factor pathway. Both small molecule and monoclonal antibody based therapies are being readied for phase 1 clinical testing in solid tumors; again these agents are intriguing candidates for treatment of MPNST and perhaps progressive PN.

\section{Treatment Trials for NF2}

Although limited insight into the molecular pathophysiology of NF2 related neoplasia precludes rational targeted drug design, several drugs that have been developed to treat sporadic meningiomas may warrant clinical evaluation in NF2 related neoplasms. Indeed, the occurrence of NF2 mutations in a significant fraction of sporadic meningiomas suggests that therapies that affect NF2 related neoplasms might have more general application. ${ }^{49} \mathrm{Sev}$ eral agents have been tested in sporadic meningiomas. Hydroxyurea is a cytoreductive drug used for many years in the treatment of adult chronic myelogenous leukemia, so that the toxicity profile is well established in adults. Hydroxyurea was reported to produce radiological responses in patients with unresectable meningiomas in a small clinical series reported from Germany. ${ }^{50,51}$ Hydroxyurea induces apoptosis in meningioma derived cell lines, leading to the hope that the drug would not require protracted administration, but studies in the United States and Canada suggest that the most frequent treatment effect is stable disease. Most patients have been treated with hydroxyurea for 1 to 2 years at most; the efficacy and toxicity of more protracted administration is unstudied, although experience with CML suggests that toxicity other than myelosuppression should be minimal in adults. ${ }^{52}$
Expression of platelet derived growth factor receptor (PDGFr) is common in sporadic meningiomas, and PDGFr antagonists may inhibit proliferation of meningioma cells. SU-101, a drug that inhibits autophosphorylation of PDGFr, is currently in phase 2 trial for patients with recurrent malignant astrocytoma; this drug has minimal myelotoxicity and is an attractive agent for clinical trial in NF2 related meningiomas. ${ }^{53}$ The drug is administered by intravenous infusion, and the long half-life of the active metabolite in serum allows administration at 14-day intervals. A substantial percentage of sporadic meningiomas express estrogen receptors, and estrogen antagonists have demonstrated efficacy in phase 2 trials in patients with unresectable meningiomas. Tamoxifen, used in doses somewhat higher than for breast cancer treatment or prophylaxis, induced radiological regression or stabilized meningiomas in a small phase 2 study ${ }^{54}$ Raloxifene, a new estrogen antagonist is being evaluated as an agent that will decrease the risk of breast cancer in women at high risk. Raloxifene has been tested in a large study of patients at risk for osteoporosis and appears to have a favorable toxicity profile. This drug warrants study in the treatment of meningiomas. There may be an increased risk of venous thromboembolism associated with raloxifene, as with tamoxifen, and the anti-estrogenic effects will be problematic for premenopausal women.

Immunomodulatory cytokines may inhibit meningioma growth. Preliminary data suggest that alpha-interferon has a direct antiproliferative effect on meningioma cells in culture, and some radiographic responses have been reported in patients. ${ }^{56}$ Interferon-alpha is administered by subcutaneous injection and the most common side effects are local inflammation at the injection site and a "flu" like syndrome. Sequential combination therapy with interferons and differentiation inducers have demonstrated synergistic activity in other tumor cell systems in vitro; further laboratory investigation is needed to determine whether this strategy is worthwhile for patients with meningiomas.

Since hydroxyurea is established as a safe but incompletely effective therapy for meningiomas, combination therapy with a differentiation inducer is an attractive strategy. ${ }^{57}$ This regimen should be tested in vitro for synergistic activity and if found to be active, could be moved into clinical trial for patients with NF2 related and sporadic meningiomas.

The clinical validation of the use of locally implantable wafers that release chemotherapeutic agents, for which the paradigm is the use of Gliodel wafers in patients with recurrent malignant glioma, ${ }^{58}$ suggests a role for such preparations in the treatment of skull base or posterior fossa meningiomas. Although BCNU is probably not the optimal drug for local treatment of meningiomas, the same wafer technology can be applied to other hydrophilic chemotherapeutic agents.

\section{CONCLUSION}

Investigators and patients both hope that the new millennium will see the development of effective treatments to benefit patients with NF1 and NF2 related neoplasms. As we begin to study possible therapies, we must be careful to design studies so that we can learn from each attempt and refine the therapeutic approaches as efficiently as possible. 


\section{References}

1. Chabner BA, Boral AL, Multani P. Translational research: walking the bridge between idea and cure-seventeenth Bruce F. Cain Memorial Award Lecture. Cancer Res 1998;58:4211-4216.

2. Huson SM, Harper PS, Compston DAS. Von Recklinghausen neurofibromatosis. A clinical and population study in south-east Wales. Brain 1988;111:1355-1381.

3. Crawford AH, Bagamery N. Osseous manifestations of neurofibromatosis in childhood. J Pediatr Orthoped 1986;6:72-88.

4. North K, Joy P, Yuille D, Cocks N, Mobbs E, Hutchins P, McHugh K, de Silva M. Specific learning disability in children with neurofibromatosis type $\mathrm{l}$ : significance of MRI abnormalities. Neurology 1994;44:878-883.

5. Hofman KJ, Harris EL, Bryan RN, Denckla MB. Neurofibromatosis type 1: the cognitive phenotype. J Pediatr 1994;124:S1-S8.

6. Hope DG, Mulvihill JJ. Malignancy in neurofibromatosis. Lancet 1981;2:1384-1385.

7. Carey JC, Laub JM, Hall BD. Penetrance and variability in neurofibromatosis: a genetic study of 60 families. Birth Defects: Original Article Series 1979;15, No. 5B:271-281.

8. Martuza RL, Eldridge R. Neurofibromatosis 2. N Engl J Med 1988;318:684-688.

9. Bouzas EA, Freidlin V, Parry DM, Eldridge R, Kaiser-Kupfer MI. Lens opacities in neurofibromatosis 2: further significant correlations. Br J Ophthalmol 1993;77:354-357.

10. Wallace MR, Marchuk DA, Andersen LB, Letcher R, Odeh HM, Saulino AM, Fountain JW, Brereton A, Nicholson J, Mitchell AL, Brownstein BH, Collins FS. Type 1 neurofibromatosis gene: Identification of a large transcript disrupted in three NFl patients. Science 1990;249:181-186.

11. Cawthon RM, Weiss R, Xu G, Viskochil D, Culver M, Stevens I, Robertson M, Dunn D, Gesteland R, O'Connell P, White R. A major segment of the neurofibromatosis type 1 gene: cDNA sequence, genomic structure, and point mutations. Cell 1990;62:193-201.

12. Viskochil D, Buchberg AM, Xu G, Cawthon RM, Stevens J, Wolff RK, Culver M, Carey JC, Copeland NG, Jenkins NA, White R, O'Connell P. Deletions and a translocation interrupt a cloned gene at the neurofibromatosis type 1 locus. Cell 1990;62:187-192.

13. Trofatter JA, MacCollin MM, Rutter JL, Murrell JR, Duyao MP, Parry DM, Eldridge R, Kley N, Menon AG, Pulaski K, Haase VH, Ambrose CM, Munroe D, Bove C, Haines JL, Martuza RL, MacDonald ME, Seizinger BR, Short MP, Buckler AJ, Gusella JF. A novel moesin-, ezrin-, radixin-like gene is a candidate for the neurofibromatosis 2 tumor suppressor. Cell 1993;72:791-800.

14. Rouleau GA, Merel P, Lutchman M, Sanson M, Zucman J, Marineau C, Hoang-Xuan K, Demczuk S, Desmaze C, Plougastel B, Pulst SM, Lenoir G, Bijlsma E, Fashold R, Dumanski J, de Jong P, Parry D, Eldrige R, Aurias A, Delattre O, Thamas G. Alteration in a new gene encoding a putative membrane-organizing protein causes neuro-fibromatosis type 2. Nature 1993;363:515-521.

15. Seizinger BR, Rouleau G, Ozelius LJ, Lane AH, St George-Hyslop P, Huson S, Gusella JF, Martuza RL. Common pathogenetic mechanism for three tumor types in bilateral acoustic neurofibromatosis. Science 1987;236:317-319.

16. Twist EC, Ruttledge MH, Rousseau M, Sanson M, Papi L, Merel P, Delattre O, Thomas $\mathrm{G}$, Rouleau GA. The neurofibromatosis type 2 gene is inactivated in schwannomas. Hum Mol Genet 1994;3:147-151.

17. Colman SD, Williams CA, Wallace MR. Benign neurofibromas in type 1 neurofibromatosis (NF1) show somatic deletions of the NF1 gene. Nat Genet 1995;11:90-92.

18. Serra E, Puig S, Otero D, Gaona A, Kruyer H, Ars E, Estivill X, Lazaro C. Servei de Genetica, Hospital Clinic, Barcelona, Spain. Confirmation of a double-hit model for the NFl gene in benign neurofibromas. Am J Hum Genet 1997;61:512-519.

19. Sawada S, Florell S, Purandare SM, Ota M, Stephens K, Viskochil D. Identification of NF1 mutations in both alleles of a dermal neurofibroma. Nat Genet 1996;14:110-112.

20. Upadhyaya M, Osborn MJ, Maynard J, Kim MR, Tamanoi F, Cooper DN. Mutational and functional analysis of the neurofibromatosis type 1 (NF1) gene. Hum Genet 1997;99:88-92.

21. Xu G, Lin B, Tanak K, Dunn D, Wood D, Gesteland R, White R, Weiss R, Tamanoi F The catalytic domain of the neurofibromatosis type 1 gene product stimulates ras GTPase and complements ira mutants of S. cerevisiae. Cell 1990;835-841.

22. Ballester R, Marchuk D, Boguski M, Saulino A, Letcher R, Wigler M, Collins F. The NFI locus encodes a protein functionally related to mammalian GAP and yeast IRA proteins. Cell 1990;63:851-859.

23. Gutmann DH, Boguski M, Marchuk D, Wigler M, Collins FS, Ballester R. Analysis of the neurofibromatosis type 1 (NF1) GAP-related domain by site-directed mutagenesis. Oncogene 1993;8:761-769.

24. Bollag G, McCormick F, Clark R. Characterization of full-length neurofibromin: tubulin inhibits ras GAP activity. EMBO J 1990;12:1923-1927.

25. Guha A, Lau N, Huvar I, Gutmann D, Provias J, Pawson T, Boss G. Ras-GTP levels are elevated in human NF1 peripheral nerve tumors. Oncogene 1996;12:507-513.

26. Gonzalez-Agosti C, Xu L, Pinney D, Beauchamp R, Hobbs W, Gusella J, Ramesh V. The merlin tumor suppressor localizes preferentially in membrane ruffles. Oncogene 1996;13:1239-1247.

27. Jacks T, Shih TS, Schmitt EM, Bronson RT, Bernards A, Weinberg RA. Tumour predisposition in mice heterozygous for a targeted mutation in NF1. Nat Genet 1994;7:353-361.

May/June $1939 \cdot$ Vol. $1 \cdot$ No. 4
28. McClatchey AI, Saotome I, Ramesh V, Gusella IF, Jacks T. The Nf2 tumor suppressor gene product is essential for extraembryonic development immediately prior to gastrulation. Genes Dev 1997;1 1:1253-1265.

29. Stiller CA, Chessells JM, Fitchett M. Neurofibromatosis and childhood leukaemia/lymphoma: a population- based UKCCSG study. Br J Cancer 1994;70:969-972.

30. Shannon KM, O'Connell P, Martin GA, Paderanga D, Olson K, Dinndorf P, McCormick F. Loss of the normal NF1 allele from the bone marrow of children with type 1 neurofibromatosis and malignant myeloid disorders [see comments]. $N$ Engl J Med 1994;330:597-601.

31. Ducatman BS, Scheithauer BW, Piepgras DG, Reiman HM, Ilstrup DM. Malignant peripheral nerve sheath tumors. Cancer 1986;57:2006-2021.

32. Wanebo JE, Malik JM, VandenBerg SR, Wanebo HJ, Driesen N, Persing JA. Malignant peripheral nerve sheath tumors. A clinicopathologic study of 28 cases. Cancer 1993;71:1247-1253.

33. Doorn PF, Molenaar WM, Buter J, Hoekstra HJ. Malignant peripheral nerve sheath tumors in patients with and without neurofibromatosis. Eur J Surg Oncol 1995;21:78-82.

34. Tuting T, Wilson CC Martin DM, Kasamon YL, Rowles J, Ma DI, Slingluff CL Jr, Wagner SN, van der Bruggen P, Baar J, Lotze MT, Storkus WJ. Autologous human monocyte derived dendritic cells genetically modified to express melanoma antigens elicit primary cytotoxic $T$ cell responses in vitro: enhancement by cotransfection of genes encoding the Thl biasing cytokines IL-12 and IFN- $\alpha$. J Immunol 1998;160:1139-1147.

35. Oettgen JF, Livingston PO, Old LJ. Immunotherapy by active specific immunization: Clinical applications: melanoma. In: DeVita V, Hellman S, Rossenberg SA, editors. Biologic therapy of cancer. Philadelphia: Lippincott, 1991:682-703.

36. Gibbs JB, Oliff A, Kohl NE. Farnesyltransferase inhibitors: Ras research yields a potential cancer therapeutic. Cell 1994;77:175-178.

37. Yan N, Ricca C, Fletcher J, Glover T, Seizinger BR, Manne V. Farnesyltransferase inhibitors block the neurofibromatosis type 1 (NF1) malignant phenotype. Cancer Res 1995;55:3569-3575.

38. Defer GL, Adle-Biassette H, Ricolf F, Martin L, Authier FJ, Chomienne C, Degos L, Degos ID. All-trans retinoic acid in relapsing malignant gliomas: clinical and radiological stabilization associated with the appearance of intratumoral calcifications. J Neurooncol 1997;34:169-177.

39. Phuphanich S, Scottt C, Fischbach AJ, Lanber C, Yung WKU. All trans retinoic acid: a phase II Radiation Therapy Oncology Group study (RTOG 91-13) in patients with recurrent malignant astrocytoma. I Neurooncol 1999;34:193-200.

40. Hong WK, Itri LM. Retinoids in human cancer. In: Sporn MD, Roberts AB, Goodman DS, editors. The retinoids: biology, chemistry, medicine, 2nd edition. New York: Raven Press, 1994.

41. Yung WKA, Kyritsis AP, Gleason MJ, Levin VA. Treatment of recurrent gliomas with high dose 13-cis retinoic acid. Clin Cancer Res 1996;2:1931-1935.

42. Rizvi NA, Marchall JC, Ness E, Yoe J, Gill GM, Truglia JA, Loewen GR, Jaunakais D, Ulm EH, Hawkins MJ. Phase 1 study of 9-cis retinoic acid (ALRT 1057) capsules in adults with advanced cancer. Clin Cancer Res 1998;4:1427-1432.

43. Rutka JT, De Armond SI, Giblin J, McCulloch JR, Wilson CB, Rosenblum ML. Effect of retinoids on the proliferation morphology, and expression of glial fibrillary acidic protein of an anaplastic astrocytoma cell line. Int J Cancer 42, 419-427.

44. Samid D, Hudgins WR, Shack S, Liiu L, Prasanna P, Myers CE. Phenylacetate and phenylbutyrate as novel differentiation inducers. Adv Exp Med Biol 1997;400A:501-505.

45. Engelhard JJ, Homer RJ, Duncan HA, Rozental J. Inhibitory effects of phenylbutrate on the proliferation, morphology, migration and invasiveness of malignant glioma cells. J Neurooncol 1998;37(2):97-108.

46. Packer RJ, Sutton LN, Bilaniuk LT, Radcliffe J, Rosenstock JG, Siegel KR, Bunin GR, Savino PJ, Bruce DA, Schut L. Treatment of chiasmatic/hypothalamic gliomas of childhood with chemotherapy: an update. Ann Neurol 1988;23:79-85.

47. Kirsch M, Strasser J, Allende R, Bello L, Zhang J, Black PM. Angiostatin suppresses malignant glioma growth in vivo. Cancer Res 1998;58:4654-4659.

48. Minchinton AL, Fryer KH, Wendt KR, Clow KA, Hayes MM. The effect of thalidomide on experimental tumors and metastases. Anticancer Drugs 1996;7:339-343.

49. Gutmann D, Giordano M, Fishback A, Guha A. Loss of merlin expression in sporadic meningiomas, ependymomas and schwannomas. Neurology 1997;49:267-270.

50. Schrell UM, Rittig MG, Anders M, Kiesewettrer F, Marchalek R, Kock UH, Fahlbusch R. Hydroxyurea for treatment of unresectable and recurrent meningiomas. II. Decrease in the size of meningiomas in patients treated with hydroxyurea. J Neurosurg 1997;86:840-844.

51. Schrell UM, Rittig MG, Anders M, Kiesewettrer F, Marchalek R, Kock UH, Fahlbusch R. Hydroxyurea for treatment of unresectable and recurrent meningiomas. I. Inhibition of primary human meningioma cells in culture and in meningioma transplants by induction of the apoptotic pathway. J Neurosurg 1997;86:845-852.

52. Cusimano MD. Hydroxyurea for treatment of meningioma. I Neurosurg 1998;98:938-939.

53. Shawver LK, Schwartz DP, Mann E, Chen H, Tsai J, Chu L, Taylorson L, Longhi M, Meredith S, Germain L, Jacobs IS, Tang C, Ullrich A, Berens ME, Hersh E, McMahon G, Hirth KP, Powell TJ. Inhibition of platelet-derived growth factor-mediated signal 


\section{Liebermann et al}

transduction and tumor growth by $\mathrm{N}$-[4-(trifluoromethyl)-phenyl]5-methylisoxazole-4-carboxamide. Clin Cancer Res 1997;3:1167-1177.

54. Goodwin JW, Crowley J, Eyre JH, Stafford B, Jaeckle KA, Townsend J. A phase 2 evaluation of tamoxifen in unresectable or refractory meningiomas: a Southwest Oncology Group study. J Neurooncol 1993;15:75-77.

55. Jordan VC. Antiestrogenic action of raloxifene and tamoxifen: today and tomorrow. J Natl Cancer Inst 1998;90:967-971.
56. Kyritsus AP. Chemotherapy for meningiomas. J Neurooncol 1996;29:269-272

57. Lingen MW, Polverini PJ, Bouck NP. Retinoic acid and interferon $\alpha$ act synergistically as antiangiogenic and antitumor agents against human head and neck squamous cell carcinoma. Cancer Res 1998;58:5551-5559.

58. Valtonen $S$, Timonen U, Toivanen $P$, Kalimo H, Kivipelto L, Heiskanen O, Unsgaard $\mathrm{G}$, Kuurne T. Interstitial chemotherapy with carmustine-loaded polymers for highgrade gliomas: a randomized double-blind study. Neurosurgery 1997;41:44-48. 